\title{
SAPF for Power Quality Improvement Based on PSODE Optimization Algorithm
}

\author{
B. Mahesh Babu, N. Uday Kumar, K. Santhosh Kumar, A. Amarendra, B. Bindhu
}

\begin{abstract}
PQ phenomenon has gain an overwhelming attention in recent years for extensive use of complicated industrial processes. In the modern world, the usage of intelligent algorithms to enhance power quality is increasing gradually as the present day utility system as a linear model is unsatisfactory and ineffective. This paper emphasis on comparative analysis of PSODE with traditional PSO and DE for the harmonic reduction in source current with optimal tuning of proportional integral (PI) controller gain values. The SAPF is dominant among the power quality conditioners used to limit the current variations that are induced in the utility system because of nonlinear loads. The reference current generation is based on $P Q$ theory. The instantaneous switching of voltage source inverter (VSI) is taken care by hysteresis band current controller (HBCC). The pro-effective simulations are implemented in the MATLAB/SIMULINK environment, which even supports the efficacy of the present day power system.
\end{abstract}

Index Terms: $P Q$ theory, power quality (PQ), particle swarm optimization with differential perturbed velocity (PSODE), shunt active power filter (SAPF) and THD.

\section{INTRODUCTION}

The use of nonlinear loads for process control application in a utility power system is the root cause of harmonic injection into the electric utility. The SAPF is the major solution to address these power quality disturbances these days. The SAPF is a power transistor technology that is presently considered as most versatile apparatus for minimization of current variations. L. Gyugyi [1] during 1970's first quoted the terminology of active power filter (APF). Even today, this research is in progress in different directions on several other issues of APFs related to arrangement, quantity, manage and setting up the apparatus.

The SAPF includes a voltage source inverter(VSI). The switching operation related to the power switches of VSI is discussed as reference generation theories or control strategies. This control strategy for the APF was first

Revised Manuscript Received on February 15, 2020.

* Correspondence Author

Dr. B. Mahesh Babu,* Assistant Professor, Department of EEE, Gudlavalleru Engineering College, A.P, India.

Uday Kumar Neerati, Assistant Professor, Department of EEE, Vasavi College of Engineering (A), Hyderabad, Telangana, India.

K. Santhosh Kumar, Assistant Professor, Department of EEE, Gudlavalleru Engineering College, A.P, India.

A. Amarendra, Associate Professor, Department of EEE, Gudlavalleru Engineering College, A.P, India.

B. Bindhu Assistant Professor, Department of EEE, CITY, Guntur, A.P, India.

(C) The Authors. Published by Blue Eyes Intelligence Engineering and Sciences Publication (BEIESP). This is an open access article under the CC BY-NC-ND license (http://creativecommons.org/licenses/by-nc-nd/4.0/) elucidated by H. Akagi [2] are in terms of supply and load current and load voltage detection. The global standard recommendations and necessities for current variation control in electrical systems impose a few limitations [3]. The power utility easily meets these standards today with the advent of power conditioners like SAPF.

Since 1970's, the power electronic based shunt APF is an striking solutions in minimizing current variations ensuring a better power quality and distribution system, as shown in Fig.1.

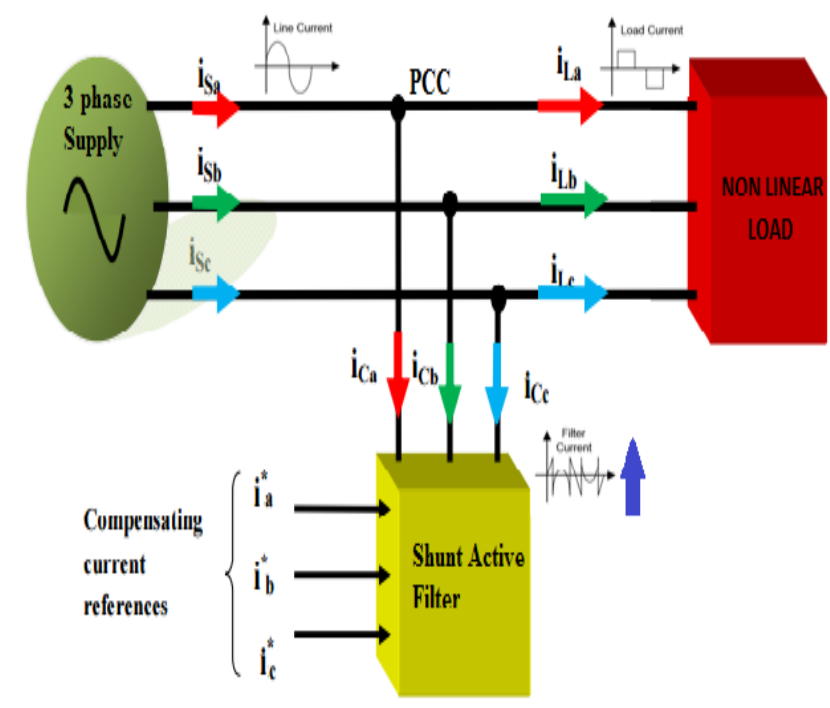

Fig.1.Illustration of SAPF in Electrical System

In literature, shunt and series APFs are the two types of APF's dominating the minimization and compensation requirements in utility systems [4]. Looking into the investigate \& advance, the SAPF is well-suited to discuss harmonics in the supply current, while the series APF is best chosen to compensate the voltage disturbances in line voltage. The APFs created by Akagi, provides, the satisfactory exhibitions of harmonic elimination [2],[5].

PI controller in the reference current theory addresses harmonic mitigation. The $\mathrm{K}_{\mathrm{P}}$ and $\mathrm{K}_{\mathrm{I}}$ gains of PI controller needs a pricise calculation. Such calculation usually for a linear sysytem with linear loads is calculated by Ziegler-Nichols, Cohen-Coon methods. But these methods contradict in case of nonlinear loads.

In recent years, heuristic algorithms [6] like genetic algorithm (GA), particle swarm optimization (PSO) [7], simulated annealing (SA), evolutionary programming (EP) and tabu search (TS) algorithms are presented to solve the PQ problems.

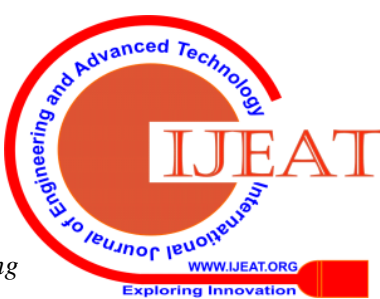


During the next few years, price and storn presented a powerful search space exploration technique called Differential Evolution (DE) to solve power problems [8], [9]. M.Basu[10] applied DE for solving the power flow problems using FACTS devices. Later, many more hybrid algorithms are introduced exploring the search space requirements.

The hybrid differential evolution (HDE) was engaged for deciding capacitor placement [8]. Finally, the obtained outcome were cheering and promising for advance research in this direction.

The present paper employs an improved hybrid algorithm called PSODE algorithm to answer the PQ problems with non soft functional signals. This algorithm is a hybridized from the principles of PSO and DE algorithms. This power electronic semiconductor technology made SAPF is a FACTS device is connected at critical point compensate the concerned power quality disturbance. The harmonics, once induced into source currents because of nonlinearity, get mitigated with the help of SAPF by injecting reverse harmonic currents into the line. The reference currents generation is based on PQ theory. Hystersis Band Current Controller by these reference currents generates the required gating pulses. The PI controller in PQ theory, along with current varaition mitigation does active and reactive power compensation. Here PI controller needs the fine-tuning of $K_{P}$ and $K_{I}$ gain values. Further, these gain values are optimized using a PSODE optimization algorithm for bettering THD.

\section{SHUNT ACTIVE POWER FILTER (SAPF)}

A $3-\phi, 415 \mathrm{~V}, 50 \mathrm{~Hz}$ generated supply is made to be transmitted to the complicated process control system which is meant to distribute to the nonlinear load. The SAPF parameter design is as follows:

The DC link Capacitor Voltage $\left(\mathrm{V}_{\mathrm{dc}}\right)$ is calculated as:

$V_{d c}=\frac{2 \sqrt{2}}{\sqrt{3}} \frac{V_{L L}}{m}$

Where, $\mathrm{m}$ : modulation index and

$\mathrm{V}_{\mathrm{LL}}$ : AC line voltage.

It is usually 1.5 times the supply voltage.

The DC link bus capacitance $\left(C_{d c}\right)$ is calculated from the following expression.

$$
\frac{1}{2} C_{d c}\left[\left(v_{d c}{ }^{2}\right)-\left(v_{d c 1}{ }^{2}\right)\right]=3 V(a I) t
$$

Where, $\mathrm{V}_{\mathrm{dc}}$ : DC reference voltage,

$$
\begin{aligned}
& \mathrm{V}_{\mathrm{dc} 1} \text { : actual DC bus voltage, } \\
& \text { 'a' : the over loading factor chosen as 1.2, } \\
& \mathrm{V} \text { : the source voltage, } \\
& \text { 'I': the phase current and } \\
& \text { ' } \mathrm{t} \text { ' : recovery time of DC bus voltage [6]. }
\end{aligned}
$$

\section{A. PQ Ttheory}

The reference current generation for mitigation of harmonic currents here is based on PQ. The Clarks and parks transformation and their inverse transformation [2-5] is the basis for PQ theory. The prime duty of this theory is fundamental component extraction using butterworth filters. The load currents and source voltages are measured and utilized for reference currents generation. The design of pq theory is illustrated as shown in Fig.2.

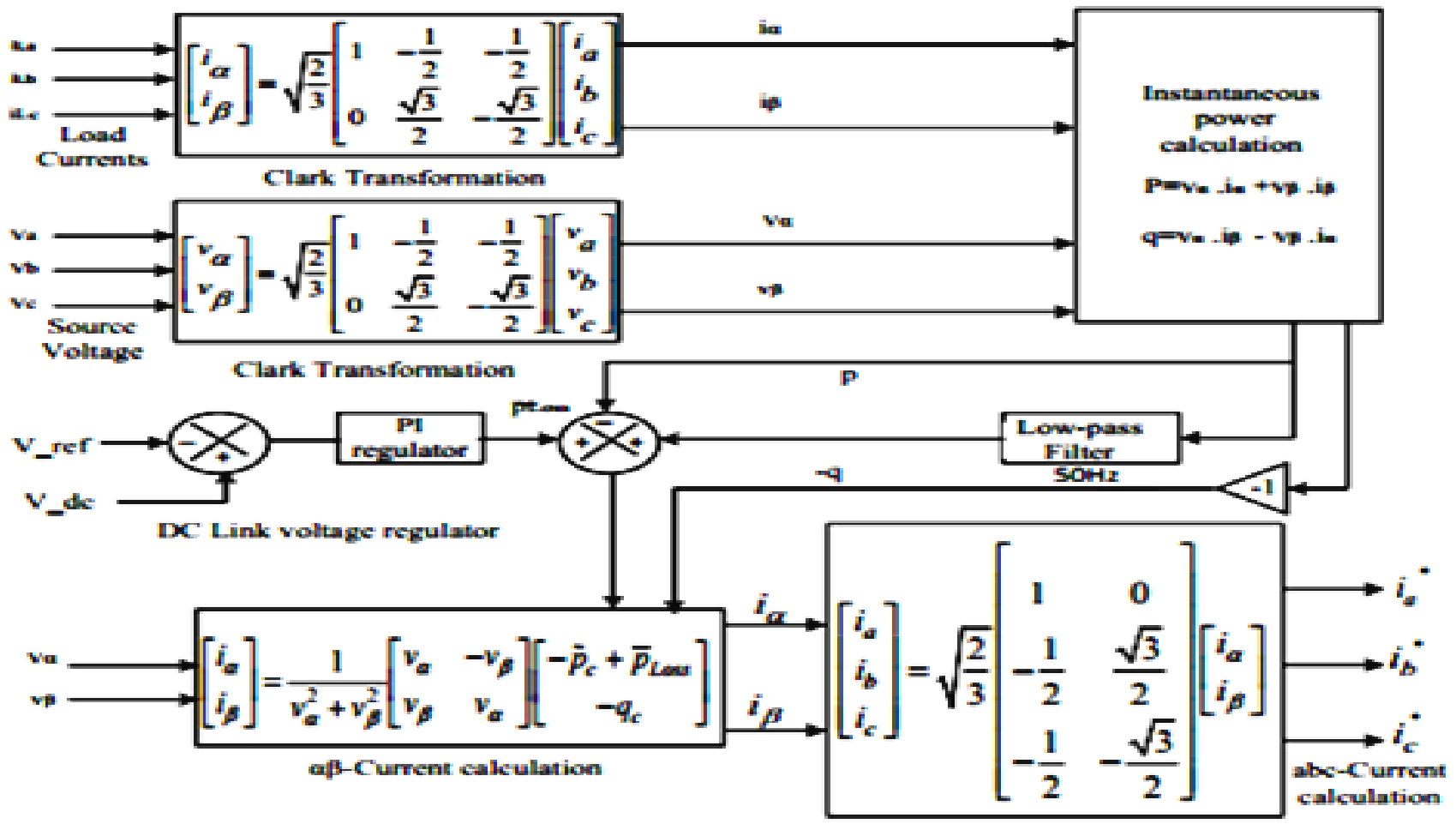

Fig.2.PQ Theory for reference current generation. 


\section{B. HBCC}

The error signal obtained from reference currents $\left(\mathrm{i}_{\mathrm{abc}}{ }^{*}\right)$ and the actual injecting currents $\left(i_{a b c}\right)$ are supplied to HBCC to generate the required gating pulses of VSI [9]. The control phenomenon is given in Fig.3.

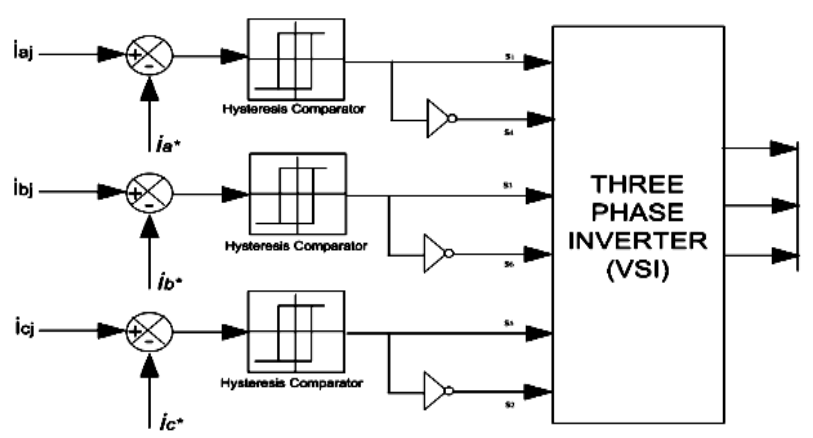

Fig.3.HBCC phenomenon and switching logic.

The outputs of HBCC are the resultant gating pulses for the six switches $\left(\mathrm{S}_{1-6}\right)$ as shown in Fig.3.

\section{PI Controller}

The $\mathrm{K}_{\mathrm{p}}$ and $\mathrm{K}_{\mathrm{I}}$ gains of the PI controller responds to the error and steady state recent past error respectively. The reference currents generated for controlling APF are based on equation (11). The output of the PI controller is as follows:

$i_{\text {loss }(n)}=i_{\text {loss }(n-1)}+k_{p}\left(V_{s n}-V_{s(n-1)}\right)+K_{i} V_{s n}$

Where, $\left(V_{s n}-V_{s(n-1)}\right)$ : the error between the reference DC link voltage $\left(\mathrm{V}_{\mathrm{dc}}{ }^{*}\right)$ and the actual DC link voltage $\left(\mathrm{V}_{\mathrm{dc}}\right)$ at the $\mathrm{n}^{\text {th }}$ sampling instant.

The placement of the PI controller is shown in Fig.2 [6].

\section{III. (PSODE $[11,13]$}

The limitation of PSO is the stagnation of particles once they have prematurely converges to any particular region of the search space. The weak local exploitation ability and low convergence velocity limitations of the search space defame DE. Now by overcoming the limitations of PSO and DE including a differential operator (from the DE algorithm) in the velocity revise method of PSO a new hybrid evolutionary algorithm called PSODE is introduced. Here the two randomly selected particles are called by the operator to the position vector. Here, in addition to the PSO mechanism, shifting of a particle to a new location when it yields better fitness value is enhanced, i.e., choice scheme is imbibed into the swarm dynamics. The two distinct particles are selected along with the particle $i(\mathrm{i} \neq \mathrm{j} \neq \mathrm{k}$, where $\mathrm{j}$, $\mathrm{k}$ are distinct particles) in PSODE algorithm. The difference vector is obtained by the difference of their positional coordinates.

$\vec{\delta}=\vec{X}_{k}-\vec{X}_{j}$

The updating of particle 'i' with d-th velocity component $(1<$ $\mathrm{d}<\mathrm{n})$ is as follows:

$$
\begin{array}{cc}
V_{i d}(t+1)=\omega \cdot V_{i d}(t)+\beta \cdot \delta_{d}+ \\
C_{2} \cdot \varphi_{2} \cdot\left(P_{g d}-X_{i d}(t)\right), & \text { if } \operatorname{rand}(0,1) \leq C R \\
=V_{i d}(t) & \text { otherwise }
\end{array}
$$

Where CR: crossover possibility,

$\delta_{d}$ :difference vector and $\beta$ : scale factor in $[0,1]$.

To have extra exploration capabilities the vector differential operator replaces the cognitive part of the velocity update formula. For $C R \leq 1$, few velocity particles will hold their past values. The past position $\mathrm{X}_{\mathrm{i}}$ with new velocity leads to a new trial location:

$\vec{T}_{r i}=\vec{X}_{i}(t)+\vec{V}_{i}(t+1)$

The better fitness value is produced when identified particle is fixed at the new. The target particle with minimization of the $\mathrm{n}$ dimensional function $f(\vec{X})$ is represented as follows:

$$
\begin{array}{lcrl}
\vec{X}_{i}(t+1)=\vec{T}_{r i} \text { if } & f\left(\vec{T}_{r i}\right) \leq f\left(\vec{X}_{i}(t)\right) \\
\vec{X}_{i}(t+1)=\vec{X}_{i}(t) & \text { otherwise }
\end{array}
$$

The particle either moves or stays at its previous location whenever there is a change in its velocity. In PSODE, $\mathrm{P}_{\text {lid }}$ always equals $X_{i d}$. So $\left|\mathrm{P}_{\text {lid }}-X_{i d}\right|$ will be the intellectual part of the algorithm which is definite, unlike in PSO. By the mutation concept the stagnant particle is moved to new location in search space for a pre determined number of iterations. The PSODE algorithm makes the swarm moment escaping the local minima problem and it is given as: if $\left(\left(\vec{X}_{i}(t)=\vec{X}_{i}(t+1)=\vec{X}_{i}(t+2)=\ldots . \vec{X}_{i}(t+N)\right.\right.$

and $\left.f\left(\vec{X}_{i}(t+N)\right)\right)$

Next, then for ( $\mathrm{r}=1$ to $\mathrm{n}$ )

$X_{i r}(t+N+1)=X_{\text {min }}+\operatorname{rand}_{r}(0,1)$

$*\left(X_{\max }-X_{\text {min }}\right)$

Where $f^{*}$ : objective functions global minima,

$\mathrm{N}$ :Number of iterations to find fitness value,

$\left(\mathrm{X}_{\max }, \mathrm{X}_{\min }\right)$ : search space bounds [11-13].

The approach procedure is clearly shown in flowchart for PSODE algorithm is as shown in Fig. 4.

\section{THE PROBLEM DEFINITION}

The objective function is defined as follows: minimize $f=$ Current variation in THD

The transfer function of the PI controller is represented by:

$G_{c}(s)=k_{p}+\frac{k_{I}}{s}$

The gain $\mathrm{K}_{\mathrm{P}}$ and the $\mathrm{K}_{\mathrm{I}}$ of the PI controller are optimally tuned by the PSODE algorithm is as shown in Fig.5.

The output of the PI controller $\mathrm{u}(\mathrm{t})$ is given by:

$u(t)=k_{p} e(t)+k_{i} \int_{0}^{t} e(t) d t$ 


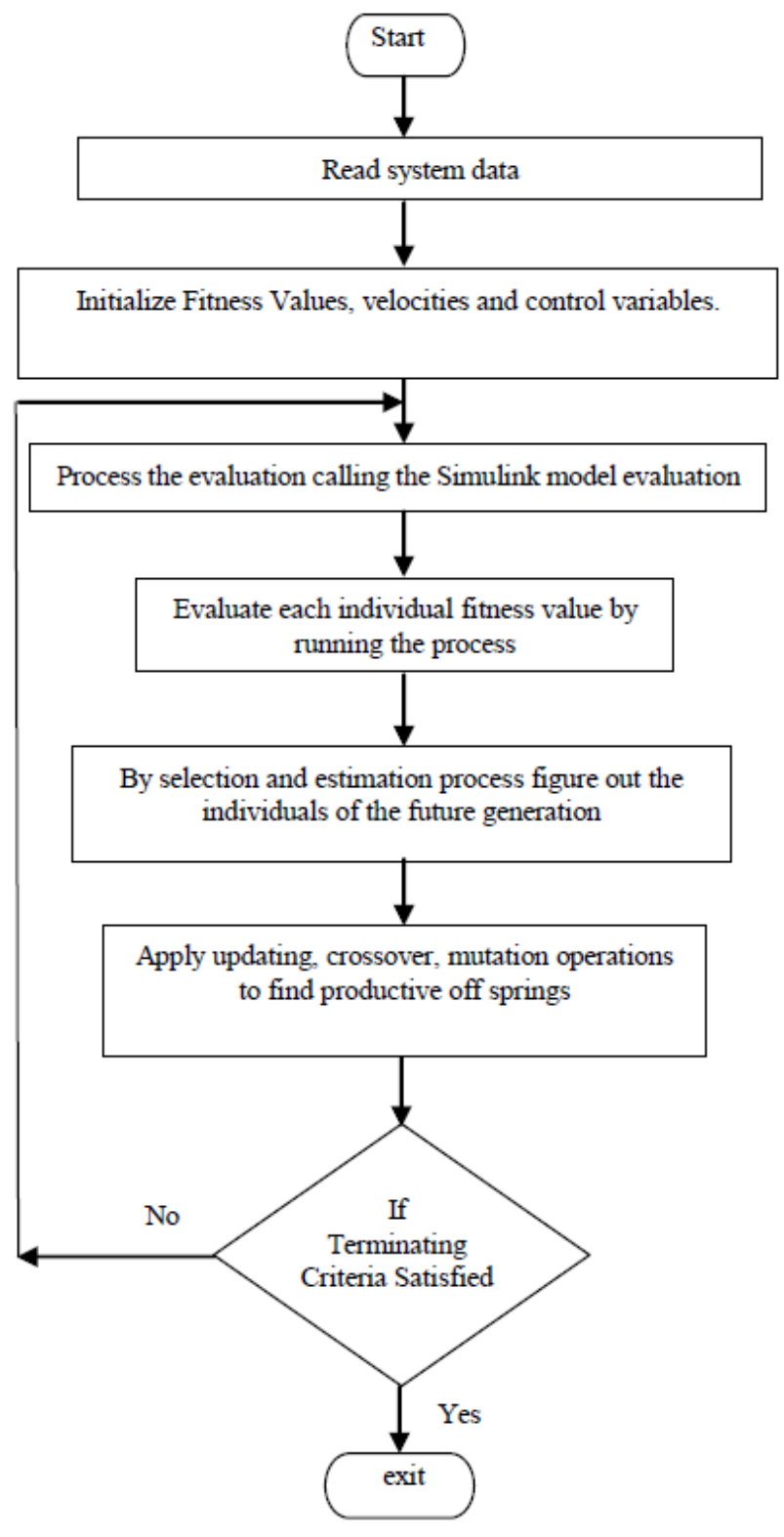

Fig.4.Flowchart of PSODE algorithm.

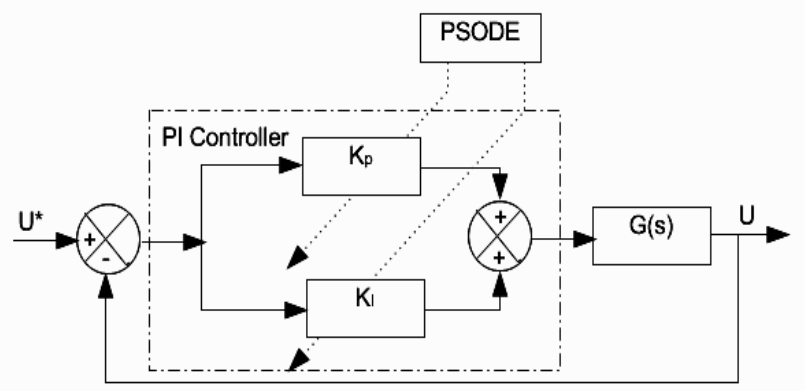

Fig.5.Control System of PI -PSO.

\section{SIMULATION RESULTS}

The effective dynamic simulation is carried out in MATLAB/Simulink environment. The PQ concerns in the present work are source current harmonics which are mainly caused due to nonlinear loads. The power electronic converters (diode bridge rectifier) with the RL load makes the nonlinear load phenomenon in the simulation environment. System parameters for simulation are given in Table I. The
SAPF developed in MATLAB/Simulink for PQ enhancement is shown in Fig.6.

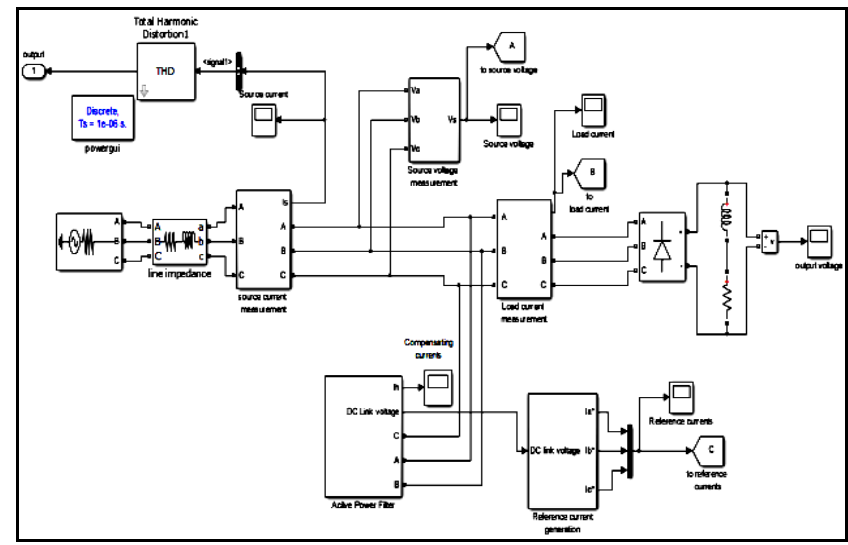

Fig.6.SAPF MATLAB/Simulink model for source current THD mitigation.

Table I. System parameters for Simulaton

\begin{tabular}{|c|c|}
\hline Parameters & Values \\
\hline Supply voltage / frequency & $415 \mathrm{~V} / 50 \mathrm{~Hz}$ \\
\hline Smoothing inductor $\left(\mathrm{R}_{5}, \mathrm{~L}_{\mathrm{s}}\right)$ & $1 \Omega, 0.1 \mathrm{mH}$ \\
\hline $\begin{array}{l}\text { Diode rectifier } \\
\text { Load resistor }\left(\mathrm{R}_{\mathrm{L}), \text { Load }}\right. \\
\text { inductor }\left(\mathrm{L}_{\mathrm{L}}\right)\end{array}$ & $\begin{array}{l}\text { 6-diode } \\
50 \Omega, 40 \mathrm{mH}\end{array}$ \\
\hline Interface inductor(R, $\left.\mathrm{L}_{\mathbf{\alpha}}\right)$ & $1 \Omega, 1 \mathrm{mH}$ \\
\hline DC side capacitance $\left(\mathrm{C}_{d d}\right)$ & $1800 \mu \mathrm{F}$ \\
\hline Reference voltage( Y d gref $)$ & $880 \mathrm{~V}$ \\
\hline Voltage source inverter & $6 \mathrm{IGBTs}_{\mathrm{s}}$ \\
\hline
\end{tabular}

The source current distortion due to the nonlinear is as shown in Fig.7(a). With no filter action the phase A, source current THD is $26.78 \%$ of FFT analysis. The compensating current generated by the PQ theory is shown in Fig. 7(b). The graphical illustration of a reduction of harmonics in the system is illustrated in Fig.7(c).

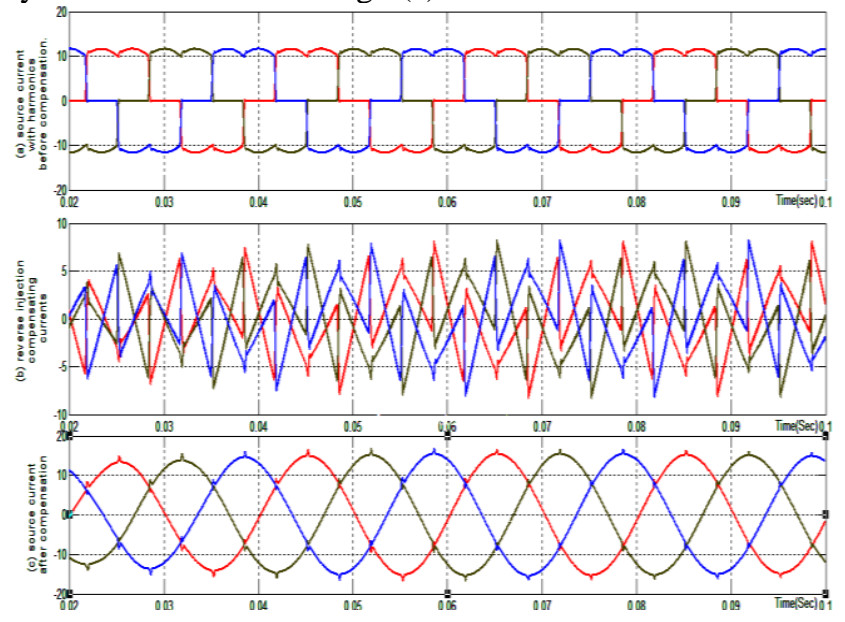

Fig.7. The simulation results of source current with PSODE Algorithm showing a) before compensation. b) The SAPF compensating currents. c) after compensation. 
The compensating currents as shown in Fig.7.(b) is injected by SAPF into utility to make ripple free source current as like Fig.7.(c).

The SAPF controlled and optimized by PSO based on the PI controller, DE based on the PI controller and PSODE based on the PI controllers are applied and discussed for comparison. PSO Algorithm based on PI controller is tested for limiting the source current. The variables considered for fitness convergence are PI controller $\mathrm{Kp}$ and $\mathrm{Ki}$ gains. In this, the population size is chosen as number 10 and the optimized control parameters and corresponding fitness values are give in the Table II. The concerned minimization fitness value of current variation THD is reduced to $1.32 \%$ (average value after 10 runs each) and $1.31 \%$ is not considered because the $\mathrm{C}_{1}$ converge to 0 value limit) making the $\mathrm{K}_{\mathrm{P}}$ and $\mathrm{K}_{\mathrm{I}}$ ranges from $(0,200)$ (By Trial and Error method) varying $C_{1}$ and $C_{2}$ (following the empirical relation $\mathrm{C}_{1}+\mathrm{C}_{2}=4$ by Trial and Error method and literature survey) where $C_{1}$ and $C_{2}$ are acceleration coefficients of PSO Algorithm. The optimization is run for 100 iterations. The PSO Algorithm fitness convergence graphs are shown in Fig.8

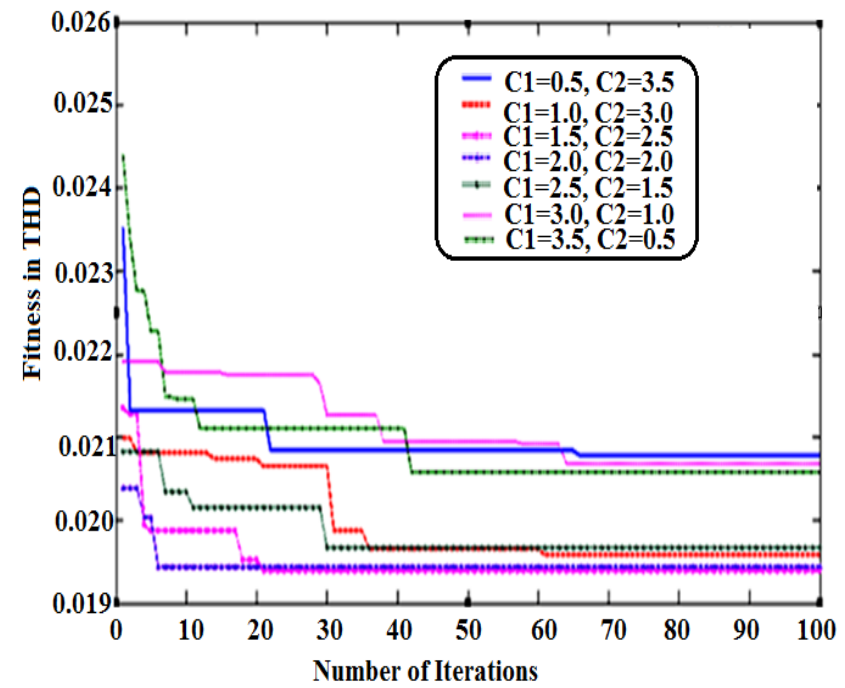

Fig.8. Source current THD Convergence of fitness with PSO Algorithm.

Table II. Control Parameter Evaluation For Source current THD Convergence of fitness with PSO Algorithm

\begin{tabular}{|c|c|c|c|c|c|}
\hline S.No & $\mathbf{C}_{\mathbf{1}}$ & $\mathbf{C}_{\mathbf{2}}$ & $\mathbf{K P}$ & $\mathbf{K I}$ & \%THD \\
\hline 1 & 0 & 4 & 3.5802 & 200 & 1.31 \\
\hline 2 & 0.5 & 3.5 & 7.1377 & 177.56 & 1.44 \\
\hline 3 & 1 & 3 & 5.315 & 184.2 & 1.37 \\
\hline 4 & $\mathbf{1 . 5}$ & $\mathbf{2 . 5}$ & $\mathbf{6 . 7 8 6 9}$ & $\mathbf{1 8 9 . 3 8}$ & $\mathbf{1 . 3 2}$ \\
\hline 5 & 2 & 2 & 16.199 & 107.67 & 1.66 \\
\hline 6 & 2.5 & 1.5 & 5.8584 & 182.84 & 1.37 \\
\hline 7 & 3 & 1 & 6.751 & 179.19 & 1.38 \\
\hline 8 & 3.5 & 0.5 & 7.257 & 179.68 & 1.39 \\
\hline 9 & 4 & 0 & 4.237 & 200 & 1.37 \\
\hline
\end{tabular}

DE Algorithm based on PI controller is tested for limiting the source current. The variables considered for fitness convergence are PI controller $\mathrm{K}_{\mathrm{P}}$ and $\mathrm{K}_{\mathrm{I}}$ gains. In this, the population size is selected as 10 and the optimized control parameters and corresponding fitness values are given in the Table III. The concerned minimization fitness value of current variation THD is reduced to $1.32 \%$ (The value after
10 runs each) tuning $K_{P}$ and $K_{I}$ in the range $(0,200)$ (By Trial and Error method) varying $\mathrm{CR}$ and F. Where CR and Fare crossover and mutation coefficients of DE algorithm. The optimization is run for 100 iterations. The DE algorithm fitness convergence graphs are shown in Fig.9. The suitable crossover rate (CR) for better optimization is 0.9 (By Trial and Error method) and Mutation constant (F) is varying between $0.5<\mathrm{F}<1$.

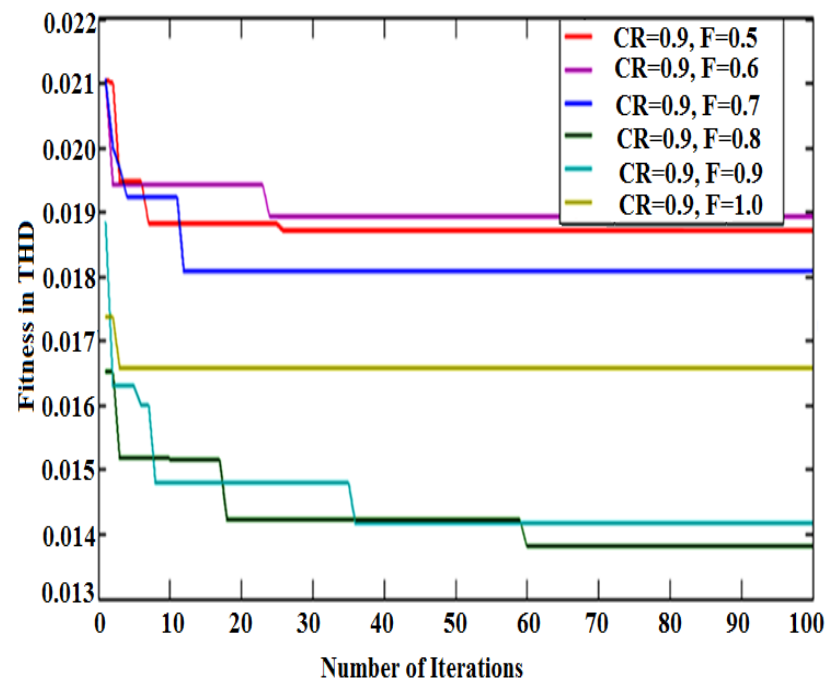

Fig. 9. Source current THD Convergence of fitness with DE Algorithm making $C R=0.9$ constant and $F$ variable.

Table III. Control Parameter Source current THD Convergence of fitness THD in SAPF with DE Algorithm

\begin{tabular}{|c|c|c|c|c|c|}
\hline \multirow{2}{*}{ S.No } & \multicolumn{2}{|c|}{$\mathbf{C}_{\mathbf{1}}=\mathbf{1 . 5}, \mathbf{C}_{\mathbf{2}}=\mathbf{2 . 5}$} & \multirow{2}{*}{$\mathbf{K}_{\mathbf{p}}$} & \multirow{2}{*}{$\mathbf{K}_{\mathbf{I}}$} & \multirow{2}{*}{ \% THD } \\
\cline { 2 - 3 } & $\mathbf{C R}$ & $\mathbf{F}$ & & & \\
\hline 1 & 0.9 & 0.5 & 5.19 & 199.78 & 1.31 \\
\hline 2 & 0.9 & 0.6 & 6.16 & 197.61 & 1.30 \\
\hline 3 & $\mathbf{0 . 9}$ & $\mathbf{0 . 7}$ & $\mathbf{3 . 2 2}$ & $\mathbf{2 0 0 . 0 0}$ & $\mathbf{1 . 2 9}$ \\
\hline 4 & 0.9 & 0.8 & 4.65 & 191.17 & 1.35 \\
\hline 5 & 0.9 & 0.9 & 4.47 & 196.71 & 1.30 \\
\hline 6 & 0.9 & 1.0 & 5.55 & 195.34 & 1.30 \\
\hline
\end{tabular}

The performance of the best combination of PSO $\left(\mathrm{C}_{2}=2.5\right)$ is applied along with Differential Perturbed Velocities to have PSODE algorithm based PI controller. The PSODE Algorithm based on PI controller is tested for limiting the source current. The variables considered for fitness convergence are PI controller $K_{P}$ and $K_{I}$ gains. The population size is chosen as 10. The optimized control parameters and corresponding fitness values are illustrated in Table IV. The concerned minimization fitness value of current variation THD is reduced to $1.29 \%$ (The best value after 10 runs) tuning PI controller $K_{P}$ and $K_{I}$ in the range (0, 200) (By Trial and Error method) varying $C_{2}$ along with $C R$ and $F$ (following the empherical relation $0<\mathrm{CR}<1,0<\mathrm{F}<1$ by Trial and Error method).

Published By:

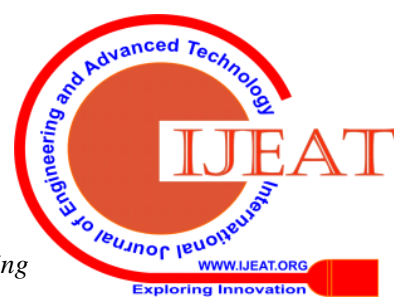


Where CR \& F are crossover \& mutation coefficients and C2 is acceleration constant of DE and PSO Algorithms respectively. The minimization criterion is processed for 100 iterations. The corresponding fitness convergence graphs with PSODE Algorithm are shown in

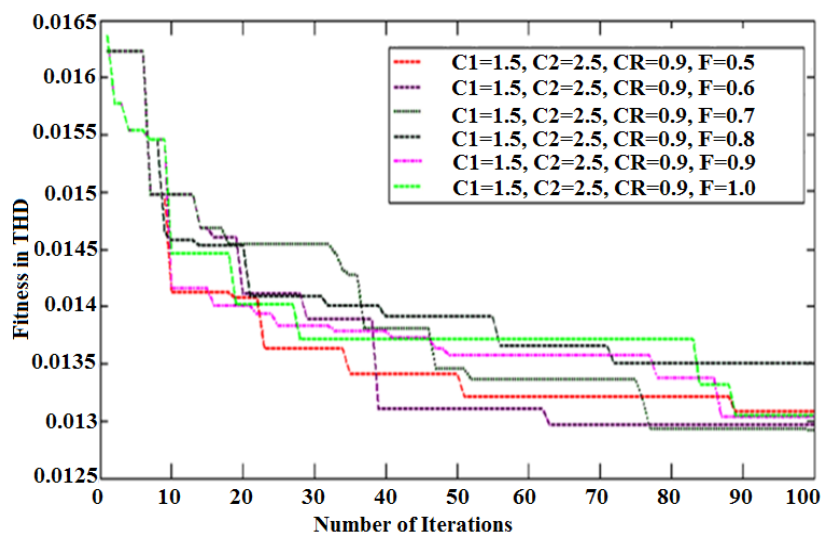

Fig. 10. The suitable crossover rate (CR) for better optimization is 0.9 (By trial and error method) and the mutation constant $(F)$ is varying between $0.5<F<1$.

Fig.10. Source current THD Convergence of fitness with PSODE Algorithm making $\mathrm{CR}=0.9$ constant and $\mathrm{F}$ variable. The main concentration is kept on how the hybridized algorithm of PSODE effectively works to overcome the limitations of PSO and DE. The comparative results are illustrated in Table V. The comparative convergence of the PSO, DE and PSODV algorithm for the best result of the 10 test runs is shown in Fig.11.

\section{Table IV. Control Parameter Evaluation For Source current THD Convergence of fitness With PSODE Algorithm}

\begin{tabular}{|c|c|c|c|c|c|}
\hline S.No. & $\mathbf{C R}$ & $\mathbf{F}$ & $\mathbf{K}_{\mathbf{P}}$ & $\mathbf{K}_{\mathbf{I}}$ & \% $\mathbf{T H D}$ \\
\hline 1 & 0.9 & 0.5 & 62.255 & 102.45 & 1.77 \\
\hline 2 & 0.9 & 0.6 & 49.942 & 98.808 & 1.79 \\
\hline 3 & 0.9 & 0.7 & 62.219 & 200 & 1.7 \\
\hline 4 & 0.9 & 0.8 & 5.2322 & 199.98 & 1.34 \\
\hline 5 & $\mathbf{0 . 9}$ & $\mathbf{0 . 9}$ & $\mathbf{5 . 2 6 2 7}$ & $\mathbf{2 0 0}$ & $\mathbf{1 . 3 2}$ \\
\hline 6 & 0.9 & 1 & 12.698 & 200 & 1.56 \\
\hline
\end{tabular}

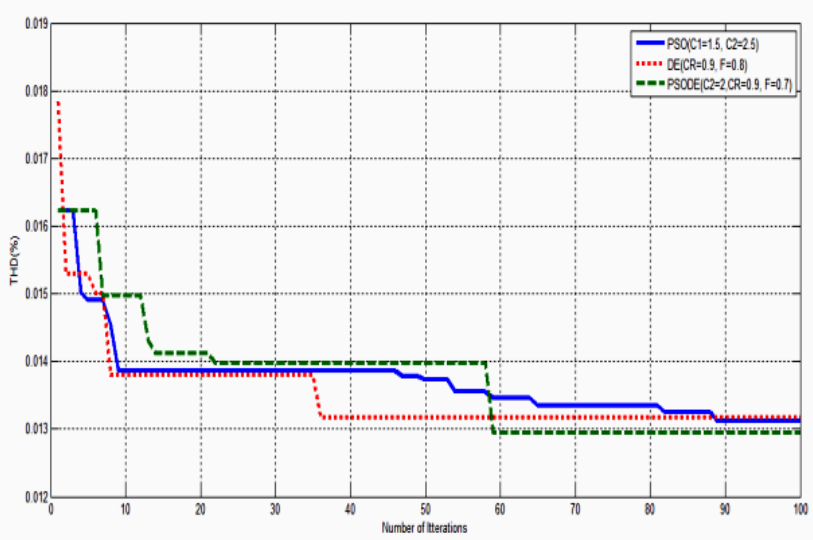

Fig.11.Comparison of Source current THD Convergence of fitness with PSO, DE, PSODE Algorithms.
Table V. Convergence of source current THD With different algorithms

\begin{tabular}{l|l|l|l}
\hline Algorithm & Best & Average & Variation \\
\hline PSO & 1.32 & 1.66 & 0.34 \\
\hline DE & 1.32 & 1.45 & 0.13 \\
\hline PSODE & 1.29 & 1.33 & 0.04 \\
\hline
\end{tabular}

Comparison of the proposed method with the other methods is given in Table VI. The proposed method is superior to other methods in reducing the THD value. Though the other methods in Table VI also got THD values less than $5 \%$ as prescribed by IEEE standards [3], it is always desirable to reduce THD as much as possible. This minimizes the heating of various equipment and mechanical stress on bearings and shafts of motors. This reduction in THD is achieved with optimizing the PI parameters and without any additional device or cost.

Table VI. The Comparison Of Source Current THD With The Other Methods

\begin{tabular}{c|c}
\hline Type of Controller/ Algorithm & THD(\%) \\
\hline PI Controller[14] & 3.84 \\
\hline Fuzzy Controller[14] & 3.59 \\
\hline Neural Controller[14] & 3.07 \\
\hline PSO Based PI & 1.66 \\
\hline DE Based PI & 1.45 \\
\hline PSODE Based PI & 1.33 \\
\hline
\end{tabular}

\section{CONCLUSION}

The comparative performance analysis of the shunt active filter based on PSO, DE, PSODE techniques are discussed in this paper. The Comparative analysis of PSO, DE, and PSODE techniques shows that PSODE Optimization has a merge over others. The limitations of PSO and DE are overcome in PSODE. The rate of convergence and searching process is better in PSODE when compared with PSO and DE. The DC link voltage is synchronized to the required level of voltage with a no time delay. The simulation results are presented to demonstrate the efficacy of the proposed algorithm.

\section{REFERENCES}

1. L. Gyugyi and E. C. Strycula, “Active AC power filter," Proceedings in IEEE, IAS Annual Meeting, pp. 529-529, 1976.

2. H. Akagi, "New trends in active filter for power conditioning," IEEE Transaction on Industry Application, Vol. 32, 1996.

3. IEEE Standard 519-1992," IEEE recommended practices and requirements for harmonic control in electrical power systems," IEEE Std 519-1992, 12 April 1993.

4. M. EI-Habrouk, M. K. Darwish, and P. Mehta, "Active power filters: A review," Proceedings in IEE on Electric Power Applications, Vol. 147, pp. 403-412, 2000

5. F. Z. Peng, H. Akagi, and A. Nabae, "Compensation characteristics of the combined system of shunt passive and series active filters," IEEE Transaction on Industry Applications, Vol. 29, pp. 144-152, 1993.

6. Sakshi Bangia, P.R.Sharama, Maneesha Garg, "Comparison of Artificial Intelligence Techniques for the Enhancement of Power Quality," International Conference on Power, Energy and Control (ICPEC), 2013. 
7. Kennedy J, Eberhart R, “ Particle Swarm Optimization,” Proceedings of IEEE international conference on neural networks, pp 1942-1948, 1995.

8. Tien-Ting Chang, "Application of differential evolution to passive shunt harmonic filters planning, "8th International Conference On harmonics and Quality of Power (Vol 1), 1998.

9. Storn R, price k, "Differential Evolution - A simple and special heuristic for global optimization over continuous spaces," J Global Optim 11:341-359, 1997.

10. Basu M, " Optimal power flow with FACTS devices using differential evolution," International Journal of electric power energy and systems, 30:150-6, 2008.

11. Das S, Konar A, Chakraborty UK, "Particle Swarm Optimization with a Differential Perturbed Velocity," ACM-SIGEVO Proceedings of GECCO’ 05, Washington D.C., pp. 991-998, 2005.

12. Angeline PJ, "Evolutionary Optimization versus Particle Swarm Optimization: Philosophy and Performance Differences," Evolutionary Programming VII, Lecture Notes in Comp Sci 1447, Springer, 601-610, 1998.

13. Swagatam Das, Ajith Abraham1 and Amit Konar, "Particle Swarm Optimization and Differential Evolution Algorithms: Technical Analysis, Applications, and Hybridization Perspectives,"Advances of Computational Intelligence in Industrial Systems, Springer, pp. 1-38, 2008.

\section{ACKNOWLEDGE}

The Work carried out is the combined work carried out by the mentioned authors. The corresponding author is ready to submit the results corresponding on conditional request.

\section{AUTHORS PROFILES}

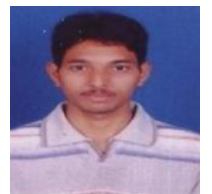

Mahesh Babu Basam, received the B.Tech degree in Electrical and Electronics Engineering from JNT University, Anantapur, India in 2009, M.Tech degree from SRM University, Chennai, India in 2011 and Ph.D degree in Electrical Engineering from JNT University, Hyderabad, India in 2019. He is currently working as Associate Professor, Dept. of EEE, Gudlavalleru Engineering College Gudlavalleru, AP, India., His Research interests include power electronics, Electric drives, optimization, soft computing applications and power quality.

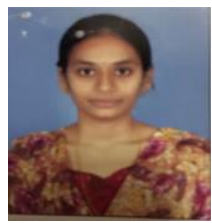

Bolagani Bindhu, received the B.Tech degree in Electrical and Electronics Engineering from KL University, A.P, India in 2013, M.Tech degree from KL University, A.P, India in 2015. She is currently working as Assistant Professor, Dept. of EEE, CITY, Guntur, AP, India., Her research interests include power electronics, power system operation and control, powe system analysis, power system optimization, power quality and soft computing applications

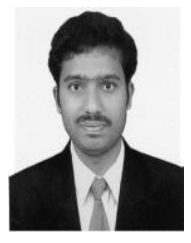

Uday Kumar Neerati, was born in Warangal, India in 1986. He received the B.Tech. and M.Tech. degrees in electrical and electronics engineering from the JNTU university, Hyderabad, India, in 2007 and 2010, respectively, Currently, he is working as an Assistant Professor in the Department of Electrical and Electronics Engineering, Vasavi college of Engineering(A),Hyderabad and pursuing his part-time Ph.D. degree at university college of engineering, Osmania university. India. His current research interests include design and efficiency improvement of power electronic converter for solar photovoltaic applications as well as power quality issues.

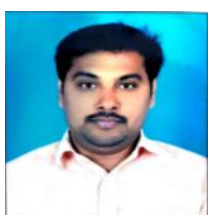

K. Santhosh kumar, was born in Hyderabad, India in 1983. He received the B.Tech. and M.Tech. degrees in electrical and electronics engineering from the JNTU university, Hyderabad, India, in 2006 and 2012, respectively, Currently, he is working as an Assistant Professor in the Department of Electrical and Electronics Engineering, Gudlavalleru Engineering College(A),Gudlavalleru and pursuing his part-time Ph.D. degree at JNTU college of engineering, JNTU university. India. His current research interests include Power Quality improvement of power electronic converter for solar photovoltaic applications as well as power quality issues.

A. Amarendra, did his B.Tech in Electrical and Electronics Engineering from Gulbarga University in 1997 and M.Tech in Electrical Power Systems

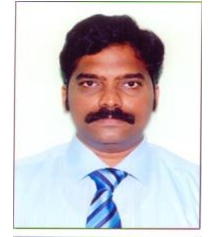

from JNTU Hyderabad in 2004; presently he is working as Associate Professor in the Department of Electrical \& Electronics Engineering, Gudlavalleru Engineering College, Andhra Pradesh, India. His areas of interest are power system security and optimization. 